07

\title{
Влияние эффектов самовоздействия на распространение импульсов поверхностных магнитостатических волн в структуре магнонный кристалл-диэлектрик-металл
}

\author{
(С) С.Л. Высоцкий, ${ }^{1,2}$ Е.С. Павлов, ${ }^{1}$ А.В. Кожевников, ${ }^{1}$ Г.М. Дудко, ${ }^{1}$ Ю.А. Филимонов, ${ }^{1-3}$ А.И. Стогний, ${ }^{4}$ \\ R. Marcelli, ${ }^{5}$ C.A. Никитов ${ }^{2,6}$
}

${ }^{1}$ Саратовский филиал ИРЭ им. В.А. Котельникова РАН, 410019 Саратов, Россия

${ }^{2}$ Саратовский государственный университет им. Н.Г. Чернышевского, 410012 Саратов, Россия

${ }^{3}$ Саратовский государственный технический университет им. Ю.А. Гагарина, 410054 Саратов, Россия

4 ГНПО „НПЦ НАН Беларуси по материаловедению“, 220072 Минск, Беларусь

${ }^{5}$ Institute for Microelectronics and Microsystems CNR-IMM, 00133 Rome, Italy

${ }^{6}$ Институт радиотехники и электроники им. В.А. Котельникова РАН, 125009 Москва, Россия

e-mail: vysots|@gmail.com

Поступило в Редакцию 28 марта 2019 г.

В окончательной редакции 28 марта 2019 г.

Принято к публикации 15 апреля 2019 г.

\begin{abstract}
Исследовано влияние эффектов самовоздействия на распространение импульсов поверхностных магнитостатических волн (ПМСВ) в структуре одномерный магнонный кристалл-диэлектрик-металл, где выбором толщины диэлектрика $h$ формируется участок аномальной дисперсии, обеспечивающий выполнение критерия Лайтхилла на формирование солитонов ПМСВ. Показано, что в тех случаях, когда вызванный металлизацией участок аномальной дисперсии совпадает с областью частот брэгговского резонанса, солитоны ПМСВ не формируются.
\end{abstract}

Ключевые слова: поверхностные магнитостатические волны, магнонные кристаллы, эффекты самовоздействия, солитоны.

DOI: 10.21883/JTF.2019.11.48334.132-19

\section{Введение}

Нелинейные спиновые волны (СВ) в магнитных пленках активно исследуются в связи с перспективой построения устройств обработки информации на их основе [1-6]. Особый интерес вызывают магнонные кристаллы (МК) [2,6] - периодические магнитные структуры, где в спектре СВ формируются запрещенные зоны на частотах брэгговских резонансов (БР) $f_{B}$, когда оказывается выполненным условие

$$
\mathbf{k}\left(f_{B}\right)^{+}-\mathbf{k}\left(f_{B}\right)^{-}=n \mathbf{K},
$$

где $\mathbf{k}^{+}$и $\mathbf{k}^{-}$- волновые векторы падающей и отраженной волн, $\mathbf{K}=\mathbf{1} 2 \pi / \Lambda$ - вектор обратной решетки, $\Lambda$ период структуры, $\mathbf{1}$ - единичный вектор вдоль оси решетки, $n= \pm 1,2, \ldots$ - порядок резонанса. При этом в окрестности частот $f_{B}$ в дисперсионной зависимости $\mathrm{CB} f=f\left(k,|\varphi|^{2}\right)$ (где $\varphi-$ безразмерная комплексная амплитуда $\mathrm{CB}$ ) могут появиться участки, на которых выполняется критерий Лайтхилла на модуляционную неустойчивость [7]

$$
\gamma \beta<0
$$

где $\gamma=2 \pi \partial f / \partial|\varphi|^{2}-$ коэффициент нелинейности, $\beta=2 \pi \partial^{2} f / \partial k^{2}$ - коэффициент дисперсионного расплывания. Было показано [7-15], что эффекты самовоздействия СВ при распространении в МК на частотах, отвечающих выполнению критерия (2), могут приводить к образованию модуляционной неустойчивости и образованию солитонов СВ. С другой стороны, известно, что в магнитных пленках дисперсия СВ выбором направления намагничивания [16-19] или металлизацией [20-23] может обеспечивать выполнение критерия (2) в отсутствие пространственной периодичности. Представляет интерес исследовать развитие эффектов самовоздействия СВ в МК в условиях, когда брэгговские резонансы формируются на участках дисперсионной зависимости $f=f\left(k,|\varphi|^{2}\right)$, где выполнен критерий (2). Цель настоящей работы - исследовать данную проблему для случая распространения импульсов поверхностных магнитостатических волн (ПМСВ) в структуре магнонный кристалл-диэлектрик-металл (МК-Д-М).

Эффекты самовоздействия проявляются при амплитудах $\mathrm{CB} \varphi>\varphi_{\text {th }}$, где $\varphi_{\text {th }}-$ пороговая амплитуда развития модуляционной неустойчивости $\mathrm{CB}$, определя- 
емая затуханием СВ в пленке [16]. Поэтому в работе рассматриваются МК на основе эпитаксиальной пленки железоиттриевого граната (ЖИГ), которые характеризуются наименьшими потерями СВ $[1,2]$. Отметим, что формирование солитоноподобных импульсов ПМСВ в МК на основе пленки ЖИГ наблюдалось в работах $[8,9]$. В работах [20-23] исследовалось формирование солитонов ПМСВ в пленках ЖИГ, разделенных воздушным зазором толщиной $h$ с металлическим экраном. При этом было показано, что формирование солитонов ПМСВ наблюдается на участках дисперсии, отвечающих длинам волн $\lambda \sim h$, тогда как на участках дисперсии, отвечающих $\lambda \gg h$ (металлизированная пленка ЖИГ) и $\lambda \ll h$ (свободная пленка ЖИГ), увеличение амплитуды волны приводит только к увеличению ширины импульса. Понятно, что в структуре МК-Д-М выбором периода МК $\Lambda$ (рассматриваются кристаллы с $\Lambda \approx 8-170 \mu \mathrm{m})$ или толщины зазора $h$ можно по разному расположить частоты брэгговских резонансов относительно участка дисперсии $\lambda \sim h$. При этом в зависимости от параметров структуры МК-Д-М и невзаимности распространения ПМСВ, проявляющейся в металлизированном МК в различии значений волновых чисел падающей и отраженной волн $\left(\left|\mathbf{k}^{+}\right| \neq\left|\mathbf{k}^{-}\right|\right)$, частоты БР могут сдвигаться „вверх“ относительно свободного МК $[24,25]$.

\section{1. Исследуемые структуры и их дисперсионные свойства}

Структуры МК-Д-М изготавливались на основе пленки ЖИГ, выращенной методом жидкофазной эпитаксии на подложке из гадолиний-галлиевого граната кристаллографической ориентации (111). Пленка имела толщину $d \approx 7.7 \mu \mathrm{m}$ и характеризовалась намагниченностью насыщения $4 \pi \mathrm{M} \approx 1750 \mathrm{G}$ и шириной линии ферромагнитного резонанса $\Delta H \approx 0.4 \mathrm{Oе}$, которые типичны для эпитаксиальных структур ЖИГ/ГГГ(111) [1,2]. С помощью ионно-лучевого травления [26] на поверхности пленки получались поверхностные периодические решетки из канавок глубиной $\delta d \approx 1 \mu \mathrm{m}$ и периодом $\Lambda \approx 8-170 \mu \mathrm{m}$. Структуры размещались в макете микрополосковой линии задержки (рис. $1, b)$ на входном 3 и выходном 4 преобразователях шириной $w \approx 40 \mu \mathrm{m}$, длиной $4 \mathrm{~mm}$, разнесенными на расстояние 6-8 $\mathrm{mm}$. На часть поверхности МК в области между антеннами (протяженностью 5.5-7.5 mm) накладывалась прокладка 8 из слюды толщиной $h \approx 150-60 \mu \mathrm{m}$, на которой размещался металлический экран 7.

Схема измерительной установки представлена на рис. 1. Макет 10 размещался в зазоре электромагнита 13 так, чтобы постоянное магнитное поле было направлено вдоль преобразователей, что соответствует случаю распространения ПМСВ [27]. Эксперименты по исследованию эффектов самовоздействия на распространение импульсов ПМСВ проводились в интервале
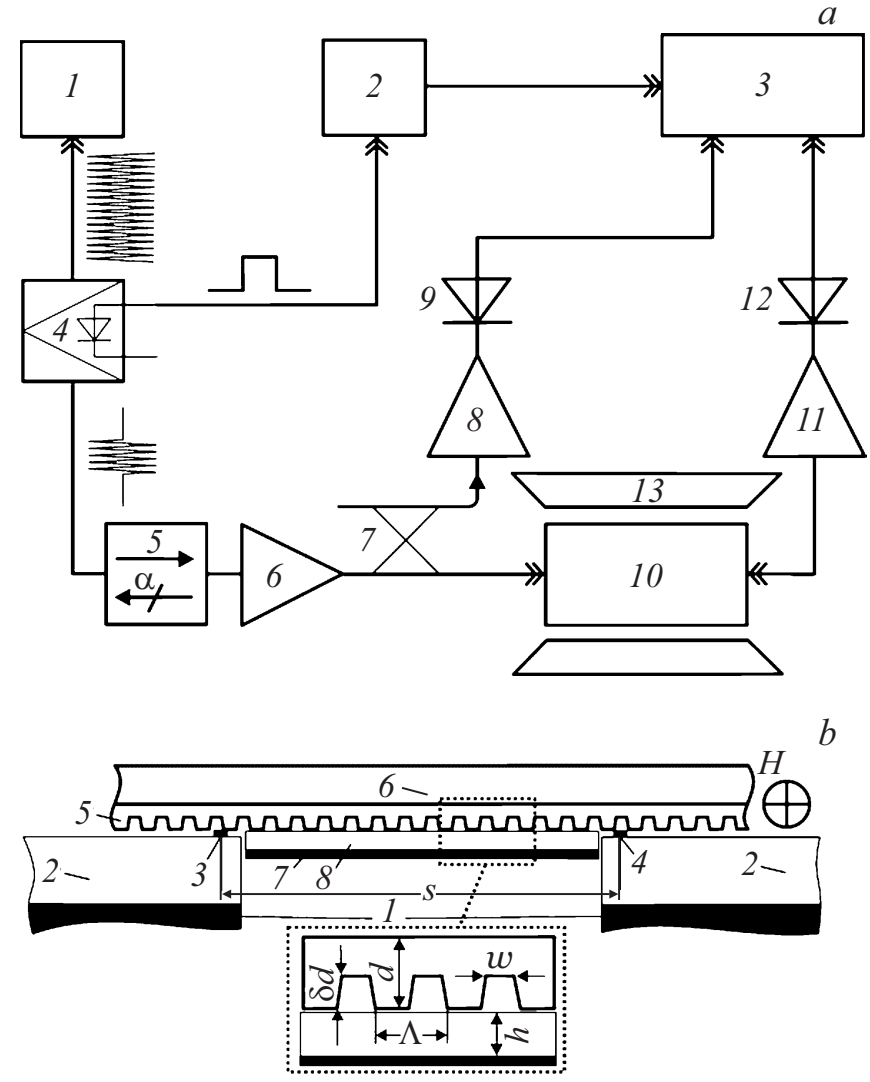

Рис. 1. $a-$ схема измерительной установки: 1 - анализатор цепей Agilent E5071C, 2 - генератор импульсов Г5-78, 3 - осциллограф Agilent infiniium MS08104A, 4 $p-i-n$-диодный модулятор, 5 - вентиль, $6-$ усилитель Agilent 87415A, 7 - направленный ответвитель, 8 - усилитель Agilent 87405C, 9,12 - детекторы, 10 - макет, 11 - усилитель МАНW 010120, 13 - электромагнит. $b-$ конструкция макета: 1 - корпус макета, 2 - поликоровые платы с антеннами, 3,4- микрополосковые антенны, 5 пленка ЖИГ, 6 - подложка из гадолиний-галлиевого граната, 7 - металлическая пластина, 8 - диэлектрическая прокладка из слюды.

полей $H \approx 740-1000$ Ое, когда параметрические процессы первого порядка (трехмагнонные) для ПМСВ запрещены законами сохранения [27]. Ниже приводятся результаты, полученные при поле $H \approx 812$ Ое.

$\mathrm{C}$ помощью анализатора цепей Agilent E5071C 1 были измерены амплитудно-частотные (АЧХ) и фазочастот-

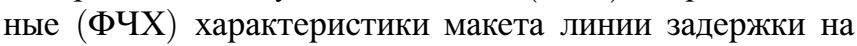
основе МК-Д-М структур с различными значениями $\Lambda$ (рис. 2). По результатам измерений определялись интервалы частот ПМСВ, отвечающие области перегиба дисперсионной зависимости $(\Delta F)$ в структуре МК-Д-М, где аналогично [20-23] выполняется условие (2), а также положение частот брэгговских резонансов относительно интервала $\Delta F$ (рис. 2). При проведении импульсных измерений непрерывный сигнал с анализатора цепей 1 на частоте $f$ через $p-i-n$-диодный модулятор 4 , управляемый генератором импульсов Г5-78 2, и вентиль 5 

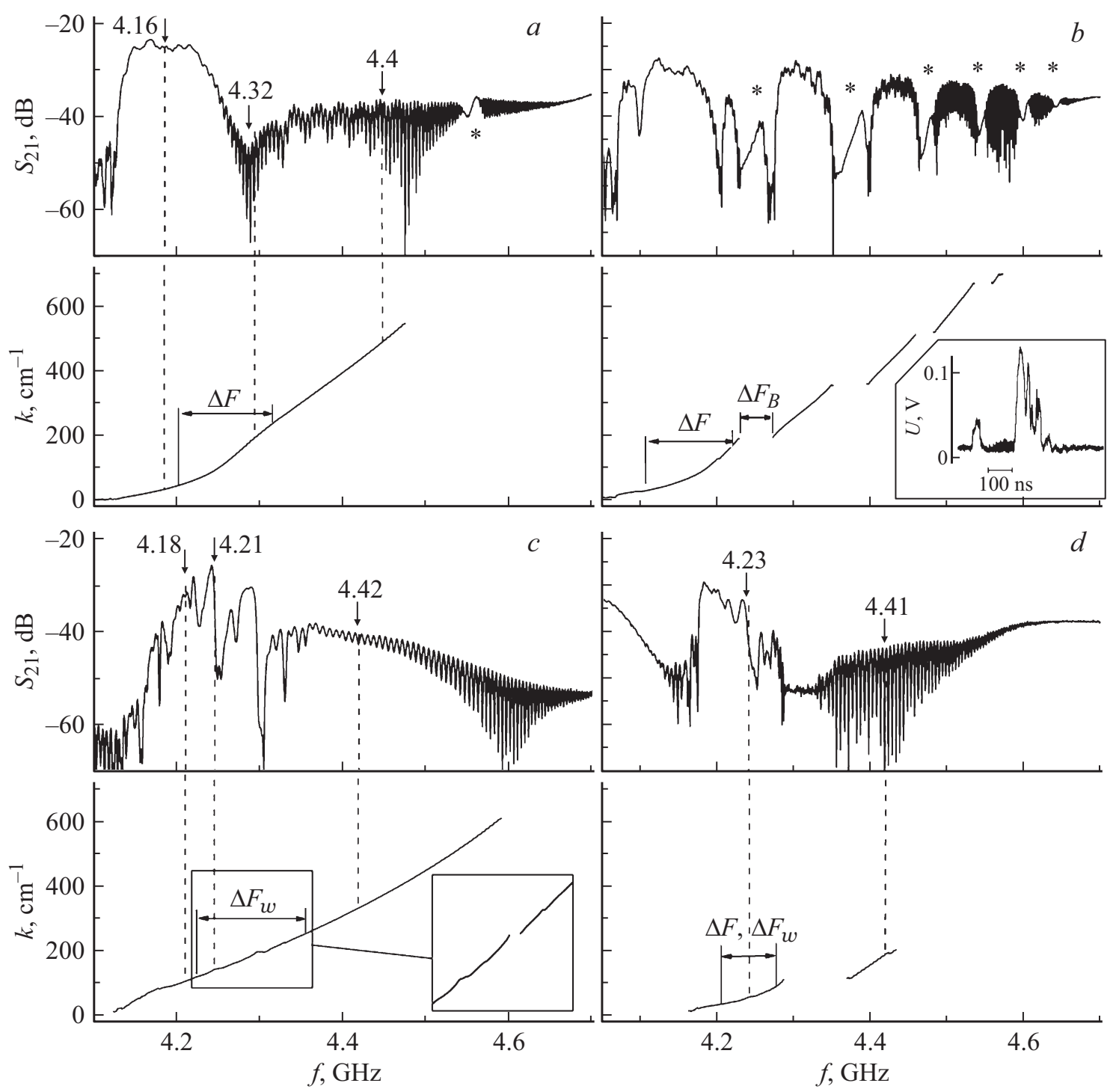

Рис. 2. Амплитудно-частотные и фазочастотные характеристики макета линии задержки со структурой $\mathrm{MK}(\Lambda \approx 50 \mu \mathrm{m})-Д-\mathrm{M}$, $\mathrm{MK}(\Lambda \approx 170 \mu \mathrm{m})-Д-\mathrm{M}, \mathrm{MK}(\Lambda \approx 8 \mu \mathrm{m}), \mathrm{MK}(\Lambda \approx 8 \mu \mathrm{m})-Д-\mathrm{M}(a, b, c$ и $d$ соответственно). Стрелки с числами у кривых указывают положение частот, для которых ниже приведены результаты импульсных измерений. Звездочками отмечены области частот, отвечающие брэгговским резонансам. $\Delta F-$ область перегиба дисперсионной зависимости. $\Delta F_{W}-$ область наблюдения аномальных участков дисперсии, обусловленных резонансами типа Фано. На вставке к рис. $2, b$ представлена характерная форма выходного импульса для частоты заполнения $4.18 \mathrm{GHz}$. На вставке к рис. 2, с изображен участок дисперионной зависимости, содержащий аномальные участки.

подавался на вход усилителя Agilent 87415А 6 и далее на входной микрополосковый преобразователь. Сигнал с выходного преобразователя усиливался с помощью усилителя Agilent 87405C 11 и после детектирования 12 подавался на вход осциллографа Agilent infiniium MS08104A 3. Для контроля формы поступающего на вход макета импульса использовался направленный ответвитель 7, сигнал с которого усиливался 8 и после детектирования 9 также поступал на вход осциллографа 3 . Генератор импульсов Г5-78 обеспечивал перестройку длительности импульса на входе макета $\tau_{\text {in }}$ in в пределах $\tau_{\text {in }} \approx 10-200 \mathrm{ns,}$ которая определялась на уровне 0.5 . Исследовалась зависимость длительности $\tau$ выходного импульса ПМСВ от уровня входной мощности $P$ и положения несущей частоты на дисперсионной кривой $k=k(f)$ (рис. 2). Величина $P$ менялась в пределах $P \approx 1-470 \mathrm{~mW}$.

Результаты измерений АЧХ $S_{21}(f)$ и зависимости $k=k(f)$, рассчитанные аналогично [28] по величине набега фазы ПМСВ для различных структур МК-Д-М при $H \approx 812$ Ое, приведены на рис. 2 .

На рис. 2, $а$ приведены результаты для структуры на основе МК с периодом $\Lambda \approx 50 \mu \mathrm{m}, \delta d \approx 1 \mu \mathrm{m}$ и $h \approx 120 \mu \mathrm{m}$. Звездочками отмечены положения БР. На участке дисперсионной зависимости $k=k(f)$ выделен интервал частот $\Delta F \approx 110 \mathrm{MHz}$, характеризующийся 

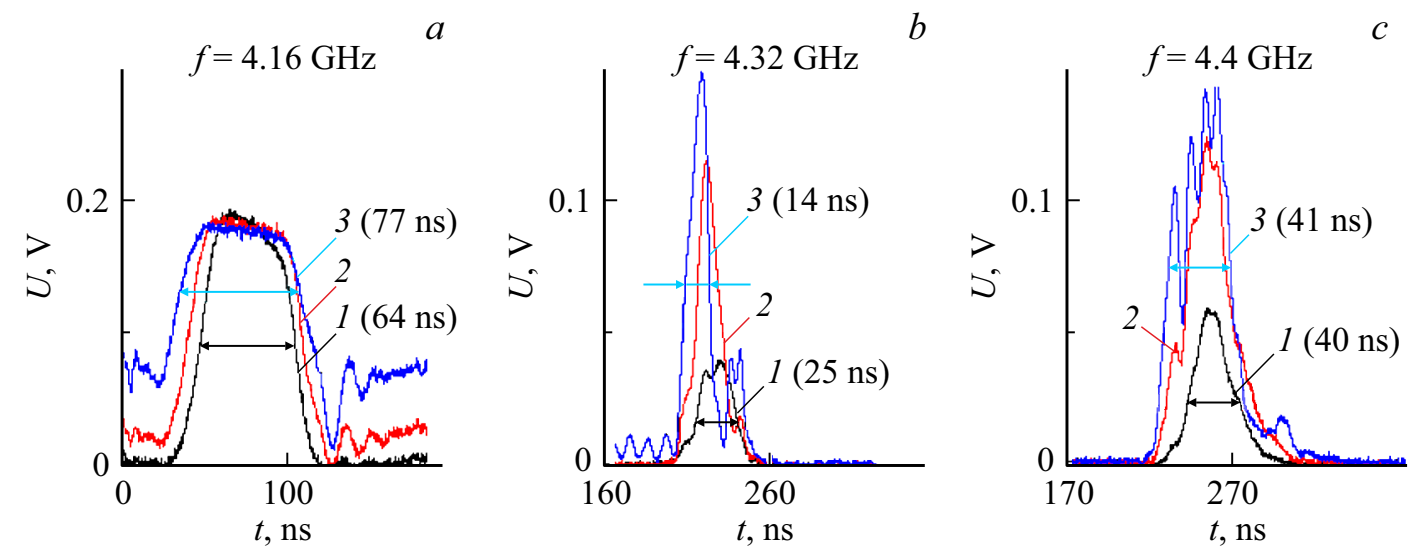

Рис. 3. Форма импульса, прошедшего через структуру МК $(\Lambda \approx 50 \mu \mathrm{m})$-Д-М при частоте заполнения $4.16,4.32$ и $4.4 \mathrm{GHz}(a, b$ и $c$ соответственно) при уровнях входной мощности 120, 300 и $470 \mathrm{~mW}$ (обозначены цифрами 1,2 и 3 соответственно). Для кривых 1 и 3 указана ширина импульсов по уровню 0.5 от максимального уровня.
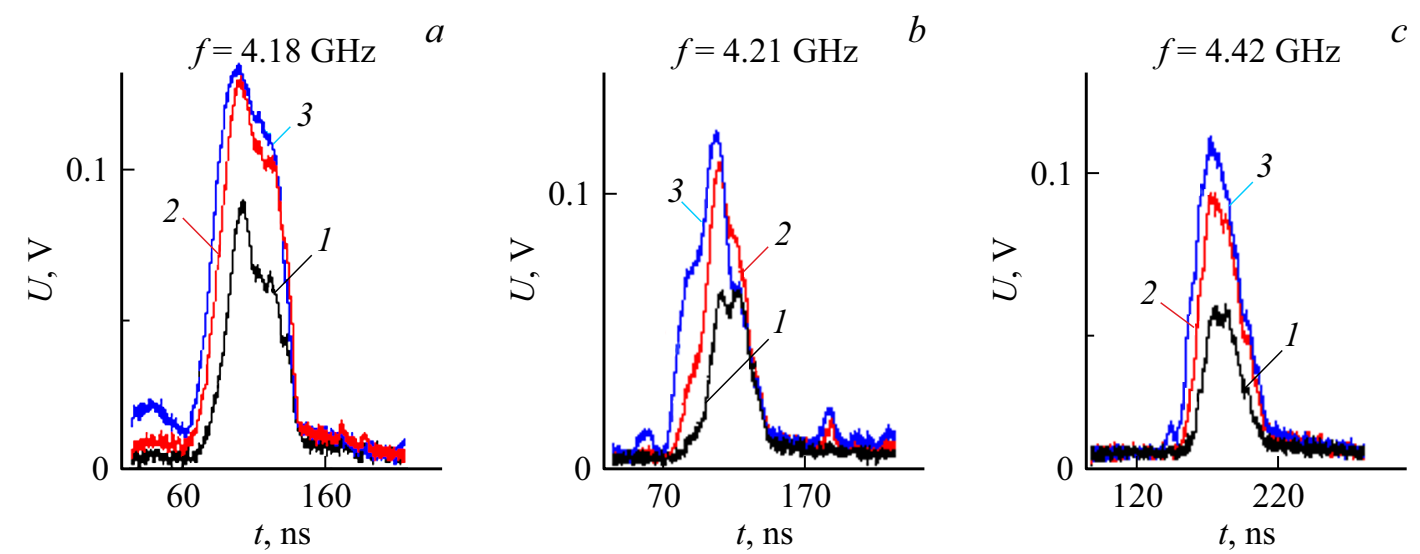

Рис. 4. Форма импульса, прошедшего через субволновой $\mathrm{MK}(\Lambda \approx 8 \mu \mathrm{m})$ при частоте заполнения $4.18,4.21$ и $4.42 \mathrm{GHz}(a, b$ и $c$ соответственно) при уровнях входной мощности 120,300 и $470 \mathrm{~mW}$ (обозначены цифрами 1, 2 и 3 соответственно).

аномальной дисперсией ПМСВ и отвечающий выполнению критерия (2). Отметим, что разворотом МК относительно антенн частоты БР для случая ПМСВ в условиях неколлинеарной дифракции смещаются „вниз“ по частоте [29], что может быть использовано как дополнительный параметр при совмещении участка дисперсии из-за неколлинеарной дифракции.

На рис. 2, $b$ приведены результаты измерений для структуры на основе МК с $\Lambda \approx 170 \mu \mathrm{m}, \delta d \approx 4 \mu \mathrm{m}$ и $h \approx 120 \mu \mathrm{m}$. Видно, что участок аномальной дисперсии, вызванный металлизацией структуры $\Delta F$, перекрывается с частотной областью брэгговской щели непропускания $\Delta F_{B}$.

На рис. 2, $c, d$ приведены результаты измерений для субволнового МК с периодом $\Lambda \approx 8 \mu \mathrm{m}$. Рис. 2 , с отвечает случаю свободного МК, а рис. $2, d-$ металлизированому кристаллу при $h \approx 90 \mu \mathrm{m}$. Из рис. $2, c$ можно видеть, что в интервале частот $\Delta F_{W} \approx 4.18-4.3 \mathrm{GHz}$ в АЧХ присутствуют узкополосные осцилляции, которым отвечают аномальные участки дисперсии. Такие резонансные особенности типа резонансов Фано в спектрах передачи и законе дисперсии ПМСВ в субволновых МК кристаллах наблюдались ранее и связывались с возбуждением обменных волн в МК [30,31]. На рис. 2, $d$ приведены результаты измерений в металлизированном субволновом кристалле при $h \approx 120 \mu \mathrm{m}$. Можно видеть, что интервалы частот $\Delta F_{W}$ и $\Delta F$ заметно перекрываются. Участок замирания интерференциии в $S_{21}(f)$ на рис. $2, d$ связан с ростом потерь ПМСВ из-за падения групповой скорости $V_{g}$ в области перегиба дисперсии.

\section{2. Влияние эффектов самовоздействия на распространение импульсов ПМСВ в структурах МК-Д-М}

При изучении эффектов самовоздействия в структуpax МК-Д-М будем, следуя методике работ [20-24], сопоставлять результаты распространения импульсов ПМСВ на частотах, отвечающих интервалу частот $\Delta F$, и частотах, выходящих за пределы $\Delta F$. При этом исходим 
из того, что на частотах из интервала $\Delta F$ выполняется критерий (2), и с ростом мощности ПМСВ можно ожидать образование солитона и уменьшения длительности выходного импульса. Наоборот, вне интервала частот $\Delta F$ рост мощности импульса будет приводить к увеличению его длительности на выходной антенне.

Отметим, что и в окрестности частот брэгговских резонансов следует ожидать аналогичного поведения импульсов прошедшего сигнала в условиях формирования солитонов [8,9].

На рис. 2 стрелками и вертикальными штриховыми линиями показно положение частот, для которых ниже приведены результаты импульсных измерений.

Необходимо отметить, что выбор длительности импульса играет существенную роль при исследовании эффектов взаимодействия для рассматриваемых структур. Во-первых, длительность импульса не должна быть слишкой маленькой, поскольку его спектральная ширина $1 / \tau$ может оказаться больше участков аномальной дисперсии $\Delta F$, что затрудняет обнаружение солитонов. С другой стороны, длительность импульса $\tau$ не должна превышать время $\tau^{*}$ развития параметрической неустойчивости СВ в пленке ЖИГ. Кроме того, мы учитывали, что при фиксированном расстоянии между антеннами $S$ в линейном режиме распространения $\left(\varphi<\varphi_{\text {th }}\right)$, существует оптимальная длительность входного импульса $\tilde{\tau}_{i n}$, при которой выходной импульс имеет наименьшую длительность по уровню 0.5 [32].

Приведенные ниже результаты, касающиеся исследования эффектов самовоздействия, получены для длительностей входного импульса $\tau_{\text {in }} \approx 40 \mathrm{~ns}$ (рис. 3-5). Мы так же показали, что время развития параметрической неустойчивости в рассмотренных структурах составляет $\tau^{*} \approx 50 \mathrm{~ns}$, для чего были исследованы огибающие выходных импульсов при максимальных уровнях падающей мощности в зависимости от длительности входного импульса (рис. 6).

\section{1. Импульсы ПМСВ в металлизированном MK с периодами $\Lambda \approx 50-170 \mu \mathrm{m}$}

На рис. 3 приведены осциллограммы импульсов, прошедших через структуры МК-Д-М с периодом $\Lambda \approx 50 \mu \mathrm{m}$ при длительности входного импульса $\tau_{\text {in }} \approx 40 \mathrm{~ns}$. Видно, что при частотах заполнения импульca $f=4.16$ и $\approx 4.4 \mathrm{GHz}$, находящихся вне частотного интервала $\Delta F$, с ростом мощности наблюдается уширение импульса. На частоте $f \approx 4.32 \mathrm{GHz}$ из области $\Delta F$ (рис. 2,a) увеличение мощности на входе приводит к сжатию импульса до $\approx 14 \mathrm{~ns}$ при максимальном уровне падающей мощности $P \approx 400 \mathrm{~mW}$.

В случае, когда частотные области брэгговских щелей перекрываются с участком аномальной дисперсии, обусловленным металлизацией структуры (рис. 2,b), нам не удалось наблюдать обужения импульса независимо от выбора частоты его заполнения. Характерная форма $a$
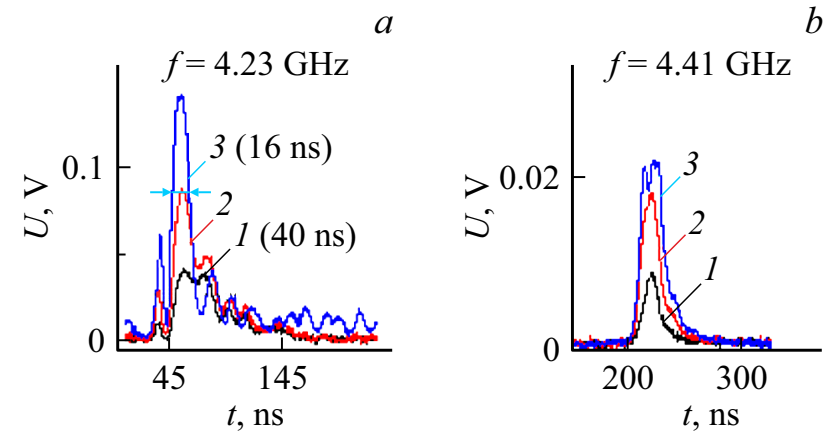

Рис. 5. Форма импульса, прошедшего через структуру субволновой $\mathrm{MK}(\Lambda \approx 8 \mu \mathrm{m})-Д-\mathrm{M}$ при частоте заполнения 4.23 и $4.41 \mathrm{GHz}$ ( $a$ и $b$ соответственно) при уровнях входной мощности 120, 300 и $470 \mathrm{~mW}$ (обозначены цифрами 1,2 и 3 соответственно). Для кривых 1 и 3 указана ширина импульсов по уровню 0.5 от максимального уровня.

выходного импульса показана на вставке к рис. $2, b$ для частоты заполнения $f \approx 4.18 \mathrm{GHz}$.

\section{2. Импульсы ПМСВ в металлизированном субволновом МК с периодом $\Lambda \approx 8 \mu \mathrm{m}$}

Рассмотрим сначала распространение импульсов в неметаллизированном субволновом МК, дисперсионная зависимость которого показана на рис. 2, c. Здесь на участке $\Delta F_{W}$ видны узкополосные участки аномальной дисперсии шириной $\sim 10 \mathrm{MHz}$, что заметно меньше спектральной ширины импульса длительностью $\tau \approx 40 \mathrm{~ns}(1 / \tau \approx 25 \mathrm{MHz})$. На рис. 4 приведены огибающие выходных импульсов ПМСВ при различных уровнях входного сигнала для частот 4.18, 4.21 и $4.42 \mathrm{GHz}$. Из рис. 2, с видно, что импульс на частоте $4.21 \mathrm{GHz}$ располагается в области резонансных особенностей в дисперсии ПМСВ $\Delta F_{W}$ (вставка на рис. $\left.2, c\right)$. Из рис. 4 можно видеть, что независимо от выбора частоты на выходной антенне наблюдается уширение импульса с ростом мощности. Такое поведение отвечает условию $\gamma \beta>0$ и отражает развитие эффектов самовоздействия, не приводящее к формированию солитонов [16,20-24].

В структуре субволновой МК-Д-М в дисперсионной зависимости вследствие влияния металла возникает аномальный участок $\Delta F$ шириной $\Delta F \approx 90 \mathrm{MHz}$ (рис. $2, d$ ). При этом интервалы частот $\Delta F$ и $\Delta F_{W}$ перекрываются. Для частоты $4.23 \mathrm{GHz}$, находящейся в пределах полосы $\Delta F$, с ростом мощности на входе наблюдается сжатие выходного импульса до значений $\tau \approx 16 \mathrm{~ns}$ (рис. 5, $a$ ). На частотах вне участка аномальной дисперсии $\Delta F$ рост мощности приводит к уширению импульса до значений $\tau \approx 45 \mathrm{~ns}$ (рис. $5, b$ ). Таким образом, наличие субволновой поверхностной структуры не препятствует развитию эффектов самовоздействия, приводящих к образованию солитоноподобных импульсов на участке аномальной дисперсии в структуре МК-Д-М. 

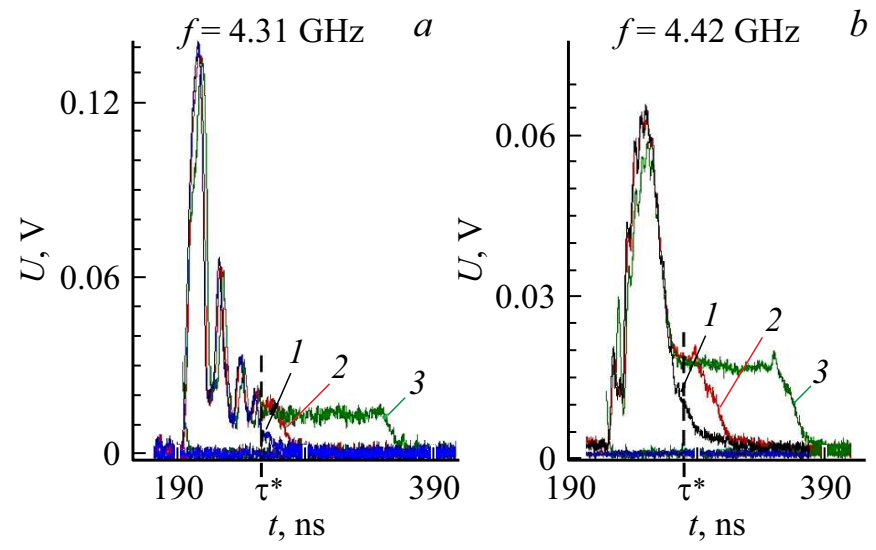

Рис. 6. Форма импульса, прошедшего через структуру $\mathrm{MK}(\Lambda \approx 50 \mu \mathrm{m})-Д-\mathrm{M}$ при частоте заполнения 4.31 и $4.42 \mathrm{GHz}$ ( $a$ и $b$ соответственно) при длительности входного импульса 40, 65 и $170 \mathrm{~ns}$ (кривые 1,2 и 3 соответственно).

\section{3. Обсуждение влияние параметрической неустойчивости на распространение импульсов ПМСВ}

Отметим, что пороги развития процессов модуляционной и параметрической неустойчивости в пленках ЖИГ достаточно близки [16]. То обстоятельство, что для импульсов СВ при выполнении критерия Лайтхилла (2) удается наблюдать формирование солитонов, связано с тем, что в спектре импульса изначально присутствуют спектральные компоненты с амплитудами, существенно превышающими тепловой уровень, и с частотами $f_{1,2}$ и волновыми векторами $\mathbf{k}_{\mathbf{1}, 2}$, удовлетворяющие законам сохранения

$$
\begin{aligned}
& 2 f=f_{1}+f_{2}, \\
& 2 \mathbf{k}=\mathbf{k}_{\mathbf{1}}+\mathbf{k}_{2},
\end{aligned}
$$

где $f$ и $\mathbf{k}$ отвечают несущей частоте и волновому вектору ПМСВ на частоте несущей в импульсе. При этом для развития эффектов самовоздействия важно, чтобы выполнялись условия

$$
\begin{gathered}
f \approx f_{1,2}, \\
|\mathbf{k}| \approx\left|\mathbf{k}_{\mathbf{1}, 2}\right| .
\end{gathered}
$$

Если при процессах (3), (4) какое-либо из условий (5), (6) будет нарушено, то неустойчивость будет носить характер параметрической [33]. При этом рождаемые параметрические спиновые волны (ПСВ) не будут находиться в синхронизме с импульсом накачки, что приводит к ограничению амплитуды выходного импульса ПМСВ [33,20-23]. Чтобы оценить возможный вклад параметрических процессов в эволюцию огибающей выходных импульсов от падающей мощности на рис. 3-5, рассмотрим влияние длительности импульса на форму выходных импульсов в рассмотренных структурах МК-Д-М.
Для определенности будем обращаться к результатам, полученным для структуры МК-Д-М с периодом $\Lambda \approx 50 \mu \mathrm{m}$, дисперсионная зависимость и АЧХ который показаны на рис. 2, $a$. На рис. 6 приведены огибающие выходных импульсов ПМСВ для частоты несущей 4.32 (рис. 6, a) и $4.42 \mathrm{GHz}$ (рис. 6, b) в зависимости от длительности входного импульса при уровне падающей мощности $P \approx 470 \mathrm{~mW}$. Можно видеть, что, начиная с длительности входного импульса $\tau=\tau^{*} \approx 55 \mathrm{~ns}$, срез выходного импульса по уровню 0.5 перестает эволюционировать с ростом длительности импульса на входе. При этом амплитуда выходного импульса ограничивается на временах $t>\tau^{*}$. Приведенные на рис. 6 результаты позволяют считать, что в рассматриваемых структурах время развития параметрической неустойчивости $\tau^{*} \geq 50 \mathrm{~ns}$. Таким образом, показанное на рис. 3-5 изменение формы импульса следует связать с влиянием эффектов самовоздействия.

\section{Заключение}

Таким образом, в работе исследовано влияние эффектов самовоздействия на распространение импульсов ПМСВ в одномерных магнонных кристаллах на основе пленке ЖИГ с периодами $\Lambda \approx 8-170 \mu \mathrm{m}$, разделенных диэлектрическим зазором толщиной $h \approx 60-120 \mu \mathrm{m} \mathrm{c}$ металлическим экраном. Показано, что в таких структурах в дисперсионной зависимости ПМСВ с длиной волны $\lambda \sim h$ формируется интервал частот $\Delta F$, на котором выполняется критерий Лайтхилла на развитие модуляционной неустойчивости. Для импульсов с частотой несущей в пределах интервала $\Delta F$ и длительностью $\tau \approx 40 \mathrm{~ns}$ меньше времени развития параметрической неустойчивости $\tau^{*} \approx 50 \mathrm{~ns}$ показано, что эффекты самовоздействия могут приводить к образованию солитонов ПМСВ лишь в тех случаях, когда частоты брэгговских резонансов оказываются вне частот $\Delta F$. Для импульсов, длительностью $\tau>\tau^{*}$, на эволюцию огибающей выходного импульса на временах $t>\tau^{*}$ доминирующее влияние оказывает параметрическая неустойчивость.

\section{Финансирование работы}

Работа выполнена при поддержке грантов Российского фонда фундаментальных исследований 18-57-00005-Бел, 17-07-01452 и в рамках Госзадания № 0030-2019-0013 „Спинтроника“.

\section{Конфликт интересов}

Авторы заявляют, что у них нет конфликта интересов. 


\section{Список литературы}

[1] Marcelli R., Nikitov S.A. Nonlinear Microwave Signal Processing: Towards a New Range of Devices. Kluwer Acad. Publ., 1996.

[2] Никитов С.А., Калябин Д.В., Лисенков И.В., Славин А.Н., Барабаненков Ю.Н., Осокин С.А., Садовников А.В., Бегинин Е.Н., Морозова М.А., Шараевский Ю.П., Филимонов Ю.А., Хивинцев Ю.В., Высочкий С.Л., Сахаров В.К., Павлов Е.С. // УФН. 2015. Т. 185. С. 1099-1128.

[3] Sulymenko R., Prokopenko O.V., Tyberkevych V.S., Slavin A.N., Serga A.A. // Low Temp. Phys. 2018. Vol. 44. P. 602. https://doi.org/10.1063/1.5041426

[4] Sadovnikov A.V., Odintsov S.A., Beginin E.N., Sheshukova S.E., Sharaevskii Yu.P., Nikitov S.A. // Phys. Rev. 2017. B. 96. P. 144428. DOI: 10.1103/PhysRevB.96.144428

[5] Chumak A.V., Serga A.A., Hillebrands B. // Nature Commun. 2014. Vol. 5. P. 4700.

[6] Ustinov A.B., Drozdovskii A.V., Kalinikos B.A. // Appl. Phys. Lett. 2010. Vol. 96. P. 142513.

[7] Chen M., Slavin A.N., Cottam M.G. // Phys. Rev. B. 1993. Vol. 47. P. 8687-8671.

[8] Дроздовский А.В., Черкасский М.А., Устинов А.Б., Ковшиков Н.Г., Калиникос Б.А. // Письма ЖЭТФ. 2010. Т. 91. Вып. 1. С. 17-22.

[9] Устинов А.Б., Дроздовский А.В., Калиникос Б.А. // Изв. вузов. Прикладная нелинейная динамика. 2012. Т. 20. Вып. 5. C. 97-111. DOI: 10.18500/0869-6632-2012-20-5-97111

[10] Drozdovskii A.V., Kalinkos B.A., Ustinov A.B., Stashkevich A. // J. Phys.: Confe. Series. 2016. Vol. 769. P. 012072.

[11] Ustinov A.B., Kalinikos B.A., Demidov V.E. // Phys. Rev. B. 2010. Vol. 81. P. 180406.

[12] Морозова М.А., Шараевский Ю.П., Шешукова С.Е., Жаманова М.К. // ФТТ. 2012. Т. 54. Вып. 8. С. 1478-1486.

[13] Morozova M.A., Nikitov S.A., Sharaevskii Yu.P., Sheshukova S.E. // Acta Phys. Polonica Series A. 2012. Vol. 121. P. 1173-1176.

[14] Морозова М.А., Шараевский Ю.П., Шешукова С.Е. // Изв. вузов „ПНД“. 2010. Т. 18. С. 113-124.

[15] Морозова М.А., Матвеев О.В., Шараевский Ю.П. // ФТТ. 2016. Т. 58. Вып. 10. С. 1899-1906.

[16] Звездин А.К., Попков А.Ф. // ЖЭТФ. 1983. Т. 84. Вып. 2. C. $606-615$.

[17] Калиникос Б.А., Ковшиков Н.Г., Славин А.Н. // Письма в ЖЭТФ. 1983. Т. 38. № 7. С. 343-347.

[18] Chen M., Tsankov M.A., Nash J.M., Patton C.E. // J. Appl. Phys. 1993. Vol. 74. N 3. P. 2146.

[19] Бордман А.Д., Никитов С.А. // ФТТ. 1989. Т. 31. Вып. 6. C. 281-282.

[20] Filimonov Yu.A., Marcelli R., Nikitov S.A. // IEEE Trans. on Magn. 2002. September. Vol. 38. N 5. P. 3105-3107.

[21] Marcelli R., Nikitov S.A., Filimonov Yu.A., Galishnikov A.A., Kozhevnikov A.V., Dudko G.M. // IEEE Trans. On Magn. 2006. Vol. 42. N 7. P. 1785-1801.

[22] Dudko G.M., Filimonov Yu.A., Galishnikov A.A., Marcelli R., Nikitov S.A. // JMMM. 2004. Vol. 272-275. N 2. P. 999-1000.

[23] Галишников А.А., Дудко Г.М., Кожевников А.В., Марчелли Р., Никитов С.А., Филимонов Ю.А. // Изв. вузов. Прикладная нелинейная динамика. 2006. Т. 14. № 3. С. 333.
[24] Mruczkiewicz M., Pavlov E.S., Vysotskii S.L,. Krawczyk M., Filimonov Yu.A., Nikitov S.A. // IEEE Trans. on Magn. 2014. Vol. 50. N 11. P. 2304103. DOI: 10.1109/TMAG.2014.2321329.

[25] Mruczkiewicz M., Pavlov E.S., Vysotsky S.L., Krawczyk M., Filimonov Yu.A., Nikitov S.A. // Phys. Rev. B. 2014. Vol. 90. P. 174416.

[26] Стогний А.И., Серов А.А., Корякин С.В., Паньков В.В. // ПТЭ. 2008. Т. 2. С. $162-165$.

[27] Гуревич А.Г., Мелков Г.А. Магнитные колебания и волны. М.: Физматлит, 1994. 464 с.

[28] Khivintsev Y.V., Filimonov Y.A., Nikitov S.A. // Appl. Phys. Lett. 2015. Vol. 106. P. 052407.

[29] Высочкий С.Л., Никитов С.А., Новиџкий Н.Н., Стогний А.И., Филимонов Ю.А. // ЖТФ. 2011. Т. 81. Вып. 2. C. $150-152$

[30] Vysotskii S.L., Khivintsev Y.V., Sakharov V.K., Dudko G.M., Kozhevnikov A.V., Nikitov S.A., Novitskii N.N., Stognij A.I., Filimonov Y.A. // IEEE Magn. Lett. 2017. Vol. 8. P. 3706104.

[31] Vysotskii S., Dudko G., Sakharov V., Khivintsev Y., Filimonov Y., Novitskii N., Stognij A., Nikitov S. // Acta Phys. Polonica A. 2018. Vol. 133. N 4. P. 508-510.

[32] Галишников А.А., Кожсевников А.В., Марчелли Р., Никитов С.А., Филимонов Ю.А. // ЖТФ. 2006. Т. 76. Вып. 5. C. $62-70$.

[33] Львов В.С. Нелинейные спиновые волны. М.: Наука, 1987. $272 \mathrm{c}$. 